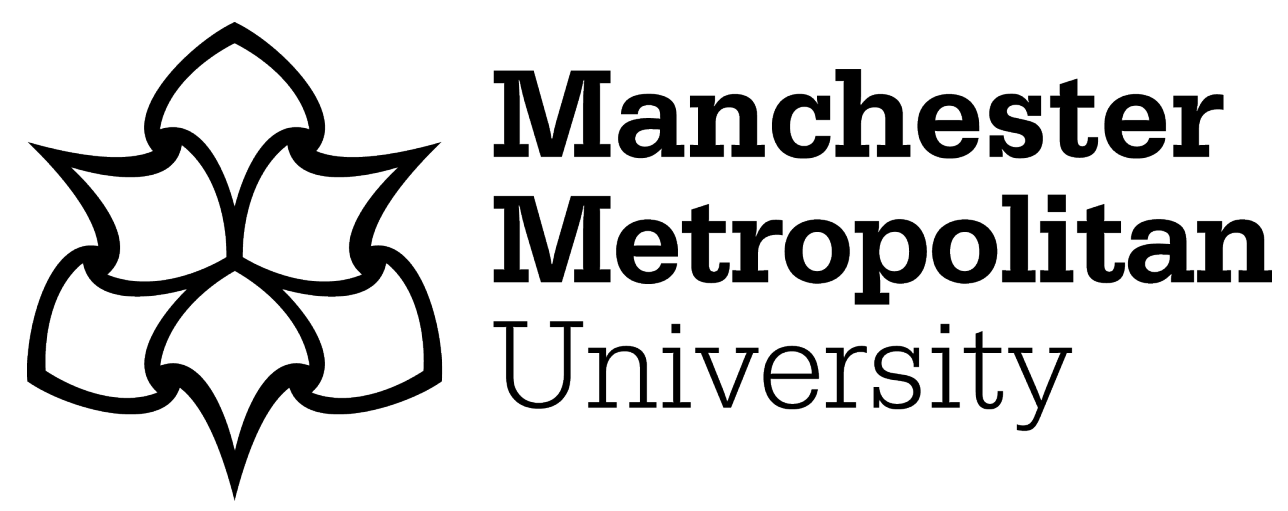

Tyler, David ORCID logoORCID: https://orcid.org/0000-0001-9736-4000 and Han, Sara (2019) Designing Products for the Circular Economy. In: Technology-driven Sustainability: Innovation in the Fashion Supply chain. Palgrave Macmillan, pp. 93-116. ISBN 978-3-030-15482-0

Downloaded from: https://e-space.mmu.ac.uk/623919/

Version: Accepted Version

Publisher: Palgrave Macmillan

DOI: https://doi.org/10.1007/978-3-030-15483-7_6

Please cite the published version 


\title{
Designing Products for the Circular Economy
}

\author{
David J. Tyler and Sara L.-C. Han
}

Reference: Tyler, D.J. and Han, S.L-C. 2019. Designing Products for the Circular Economy. In: Vignali, G., Reid, L.F., Ryding, D. \& Henninger, C.E. (eds). Technology-driven Sustainability; Innovation in the Fashion Supply Chain. Palgrave Macmillan. Chapter 6, 93-116.

\section{Introduction}

The advance of globalisation has stimulated many initiatives in the US and Europe. The Quick Response strategy was developed in the 1980s to retain a competitive advantage for domestic manufacturing; the internet has made fast electronic communication a global phenomenon; and the rapid acquisition of technical skills in numerous countries has meant that many professional tasks could be outsourced (quality control, materials purchasing, sample making, fabric cutting, etc.). Gereffi (1999) identified these trends for the apparel and textile sector. The trends have continued and globalisation has become the norm. Domestic industrial activity in the US and Europe has dwindled.

This chapter is concerned with the design process and the skills needed to make a success of Circular Economy ambitions. How has the design process been affected by globalisation? Do companies seeking to implement Circular Economy concepts need to revisit the way design is managed?

The thesis developed in this chapter is that the Circular Economy requires a radical culture change throughout the supply chain, and that the design process is at the heart of the necessary transformation. Whereas measures to improve the sustainability of products can be "bolted on" to existing management structures, the Circular Economy requires companies to go back to the drawing board to set up processes that are fit for purpose.

The word sustainability can take different meanings depending on context. However, all the meanings endorse the wording of the World Commission on Environment and Development: sustainable development is development that "meets the needs of the present without compromising the ability of future generations to meet their own needs." (Our Common Future, 1987). In the world of business, the primary sense is that of economic efficiency (leading to consideration of innovation in products and services, to growth and long-term prosperity, and to measures increasing productivity). Those interested in sustainable social development tend to focus on indicators of community well-being (the reduction of poverty, growth of entrepreneurial initiatives, improvements in public health, and respect for human rights). The champions of environmental sustainability give their attention to impacts affecting the land and the seas. This principle is applied to the use of the Earth's resources, the production of wastes, the way we use products and the way they are discarded when they have no further use to the owners. This chapter uses the term sustainability in the latter sense.

The term Circular Economy (CE) is more problematic. Kirchherr et al. (2017) have analysed 114 definitions gathered from academics and practitioners. They find many indicators of an immature discipline:

"The circular economy (CE) concept is trending and thus much lip service is given to it these days. Trending concepts tend to diffuse in their meaning and many have claimed that this has also happened to the CE concept."

They point out the difficulty for people using the term:

"We note that this abundance of CE conceptualizations, this 'circular economy babble', constitutes a serious challenge for scholars working on this topic. [. . .] If scholars are not aware of their conceptually different understanding of $\mathrm{CE}$, knowledge accumulation attempts may lead to misleading results."

Rather than enter into a discussion of meanings, this chapter adopts a definition of CE given by WRAP (2018):

"A circular economy is an alternative to a traditional linear economy (make, use, dispose) in which we keep resources in use for as long as possible, extract the maximum value from them whilst in use, then recover and regenerate products and materials at the end of each service life."

This has the merit of contrasting traditional production (linear) with a pathway that treats wastes as resources (circular). The definition brings out several important elements of the strategy: extending useful life, improving efficiencies of use of resources, followed by recovering and regenerating materials at the end of the service cycle.

In the pre-globalisation years, the first drivers for improved environmental practices were legislative. This is the theme of the first section. 


\section{Legislative drivers}

Considering just the UK, early environmental legislation set out to clean up the rivers, the air, and the land. In 1937, trade effluent could be discharged into the public sewer only by satisfying quality standards and only with the consent of the regulatory body. Health hazards posed by smoke in Manchester and other industrial centres stimulated local restrictions on discharges to the atmosphere, but it took over 4000 deaths from London smogs to bring in the Clean Air Act of 1956 (Heys, 2012). The Water Act 1989 made many changes to the provision of clean water to consumers and industry, but particularly it empowered the National Rivers Authority to manage pollution and established the principle that the polluter pays for damage done. A year later came the Environmental Protection Act, which introduced a system of integrated pollution control for the disposal of wastes to land, water and air. A key development was to introduce the concept of "statutory nuisance". Those fitting this description are defined as "premises which are deemed to be detrimental to health or a nuisance, or are emitting dust, steam, smells, effluvia or noise with this effect" (Defra, 2011). The concept of "contaminated land" was introduced a shortly afterwards with the Environment Act 1995. The major impact on the textile sector was on dye-houses and the effluents they released into the rivers. The effect was to either compel businesses to install water treatment plants or to close their doors in the UK. This 'end-of-pipe' intervention achieved a significant improvement in environmental sustainability.

In the 1990s, EU regulation became more prominent, subsuming national initiatives. In 1994, a directive was issued on packaging and packaging waste. This set out targets for the reduction of landfill by recycling and reuse of packaging materials. The concept of "producer responsibility" was subsequently introduced so that producers were responsible for ensuring the recycling and reuse targets were met. These regulations affected the whole of the apparel supply chain, with managers and technologists finding ways to satisfy the regulators.

Until recent years, apparel product design has been undertaken without reference to environmental regulation. However, the legislative framework has increasingly constrained design decisions relating to the use of hazardous chemicals, especially with the advent of REACH regulations within the EU (Registration, Evaluation, Authorisation and restriction of Chemicals). REACH was introduced in 2006, replacing 40 previous legal documents (European Commission, 2018). As the acronym indicates, according to the principle of producer responsibility, companies are required to register all chemical products being offered for sale and to test them using specified protocols. The results are then evaluated by the European Chemicals Agency and substances are either approved for sale, authorised for restricted use, or banned altogether if they pose an unacceptable risk to health or the environment. Most retailers and brands now have their own lists of the large number of chemical substances that are prohibited in the dyeing and finishing of textiles. This information is known in the trade, but is largely the province of technologists and managers. Those involved with design are aware of REACH but have no direct involvement with the process.

Consequently, whilst legislation is affecting the textile/Apparel sector in many ways, the response is primarily for technical solutions to be found at the locations where problems are observed. The emphasis is on compliance. It is significant that the design process continues without needing to address any of these environmental issues.

\section{Design for sustainability in use}

The increasing adoption of environmental management systems has expanded the vision for initiatives promoting sustainability, including laundering and care. Principles for product design and development are recognised that will lead to more sustainable goods and services. As identified by Cooper et al. (2013), the design stage is the key phase in which to introduce strategies to increase product longevity, and thereby create opportunities for the greatest resource savings throughout the product lifecycle. Spangenberg and Lorek (2002) calculated that although $80-90 \%$ of a products' environmental impact occurs throughout the use phase, over $80 \%$ of these impacts are determined at the design stage. If the average life of garments were to be extended by one third, and the need for new clothing reduced, the carbon, waste and water footprint of apparel could each be reduced by more than $20 \%$ (Gracey and Moon, 2012). Areas fundamental to determining longevity and durability at the design stage encompass: size and fit, fabric quality, colour and style, and care practice information (Cooper et al., 2013). Consumers' understanding and adoption of circular economy practices into their own personal identities is also key to the success of sustainable design strategies.

Fashion consumers constantly reconstruct their own identities by modifying and incorporating fashion styles, rules and acts into their own self-reflection and individuality (Niinimäki, 2010). Designing for a responsible identity addresses the imperative to make sustainable design strategies appealing to consumers as information 
and practices which they can incorporate into their own personal representations of themselves as individuals. Consumers want to behave ethically and identify with ethical practices, but feel judged when their failure to do so is highlighted by the more virtuous actions of others (Zane et al., 2016). In order to mitigate this effect, production best practice needs to be translated into clear and engaging information for consumers, so that they can feel included in the message of good practice, without feeling that others with more knowledge stand in judgement over them (Zane et al., 2016). Consumers can also be encouraged to maintain and value their garments through the development of ongoing emotional and empathetic relationships between wearers and garments (Gwilt, 2014). By identifying a garment with a significant, positive emotional experience, event or narrative, a sense of meaningful connection and attachment to a garment can be created (Connor-Crabb et al., 2016).

Products designed with new models of consumption in mind may also encourage consumers to strengthen the person-product relationships, and hence postpone early product replacement (Mugge et al., 2005). Creating products that can be customised in the design (or re-design) process enables greater personalisation (Niinimäki, 2013; Connor-Crabb et al., 2016). As stated by Bocken et al. (2017):

"A circular economy aims to keep products, components, and materials at their highest utility and value at all times. The value is maintained or extracted though extension of product lifetimes by reuse, refurbishment, and remanufacturing as well as by closing of resource cycles - through recycling and related strategies. An alternative strategy for the extension of product lifetimes through sharing them or making them multifunctional. All these strategies may be facilitated through changes in ownership relationships, such as leasing and product-service systems"

Shared or collaborative consumption can be defined as the coordinated acquisition and distribution of resources, such as swapping and resale (Park and Armstrong, 2017). Designing products for shared use or collaborative consumption necessitates purposeful design considerations such as designing in greater durability, versatility, multifunctional uses, modularity and low wash frequency. Modular design in particular, refers to multifunctional garments that can be altered by the wearer to bring greater variety into a wardrobe (Niinimäki, 2013). Design considerations that meet these specific needs, rather than market place 'wants', offers the potential to reduce the overproduction of unnecessary products, limiting resource use in both production and distribution (Gwilt, 2014).

The use phase is the second most dominant lifecycle phase for clothing, however, wash frequency is dominated by subjective standards of personal cleanliness, about which there is little agreement (Gracey and Moon, 2012; Gwilt, 2014). In the UK, the average adult owns around 100 items of clothing, and washes between 274 and 343 items each year. The financial cost of this is estimated to be $\sim £ 3.4$ billion (including electricity, water, wastewater and detergent). The use phase represents just over $26 \%$ of total greenhouse gas emissions in the total lifecycle. Washing is the largest contribution to this (15\% of the total), followed by drying ( $10 \%$ of the total). Consumer research has that found laundry practices do appear to be changing, with evidence of good practice but potential for further change: A high proportion of people wash full loads and at low temperatures, although around a third do not normally sort clothes (to facilitate more efficient washing/drying) and nearly a quarter use tumble driers in summer. Consumers have expressed a willingness to consider wearing clothes for longer before putting them in the laundry (Gracey and Moon, 2012).

\section{Design for Environment and Design for Disassembly}

The impact of producer responsibility regulation has been noted already for packaging waste. Some industries, particularly those involved with electrical and electronic equipment, have extended obligations placed on them (EPR). The procedures implemented in Japan, Germany, Switzerland and China are described and compared by Wang et al. (2017). In essence, producers are required to take responsibility for the takeback, recycling and disposal of the waste electrical and electronic equipment (WEEE) that these companies release to the market. Faced with significant additional costs, many of these companies have considered how design decisions affect end-of-life processes. The producer responsibility obligations have triggered thinking about Design for Environment (DfE), Design for Disassembly (DfD) and Design for Disposal.

Twenty years ago, it was possible to report quantifiable benefits for companies responding to WEEE regulation and examples were supplied by Bhamra et al. (1998). In the intervening years, product development tools have been improved and significant progress has been made to identify design principles. As an example, a case study on mobile phones is provided by Long et al. (2016:5):

An additional benefit of forcing this cost onto the producer is that they are encouraged to make their EEE products as easy as possible to recycle or dispose as they have to pay to cover the costs of such actions. This motivates the producer to design their products to contain fewer hazardous substances, 
lower the chance of obsolescence or failure and be easier to recover value from during the recycling process as this will reduce the EOL [end of life] expenditure faced. At the same time, companies may be able to use the recycled material to repair or manufacture new EEE products at a reduced cost.

A voluntary extended producer responsibility scheme for carpets is in place in the USA (Choi, 2017). After two years of negotiation, in 2002 the industrial sector was given the liberty of establishing its own approach to recycling. Targets were set: to achieve a diversion rate from landfill of $10 \%$ by 2005 and $23 \%$ by 2010 . Due to the technological challenges, to variations exhibited by the organisations involved, and to the location of recycling businesses, three business models emerged. These were: in-house recycling, recycling and supply, and small independent recyclers. Whilst economic and environmental factors are analysed, Choi's paper records that the sector did not reach its goals on recycling rates. Significantly, Choi makes no mention of the role of design, and the main strategy identified is to search for residual value in post-consumer waste.

Contrast the USA experience with that of the UK. Again, the extended producer responsibility scheme for carpets is voluntary, coordinated by Carpet Recycling UK that was established in 2008. They report that the diversion rate for carpets (from landfill) has increased from 2\% in 2007 to 42\% in 2017 (Carpet Recycling UK, 2018). The strategy is to move towards implementation of the Circular Economy, connecting design with the collection, reuse and reprocessing of carpets. Gardner (2017) made a direct link between the redesign of carpets and the development of technologies to produce recyclable carpets in the future.

This link between design and technology is apparent in the work of the Dutch company Niaga (2018)

At Niaga - the word again spelled backwards - we redesign every day products from scratch. Our aim is to make products fully recyclable in an easy and affordable way, without compromising on quality or price. Carpet was the first product we redesigned, and today we offer our carpet manufacturing technologies to make carpet that can be fully recycled back into new carpet.

Companies in Europe and the US are now offering products for sale that have been manufactured using this technology.

Mohawk Industries launched their product Air.O in the US market in early 2017. Air.O is made with Niaga ${ }^{\circledR}$ Technology, and represents an entirely new flooring category called Unified Soft Flooring (USF). Air.O eliminates the "new carpet smell", is easy to install and is $100 \%$ recyclable (Niaga, 2018).

If products have not been designed with recycling in mind, it is not surprising that the processes of recycling are complex and expensive. However, when product design operates within a circular economy framework, there is potential for recycling processes to be simplified and made much more cost effective. This is where product development tools (assisting with environmental sustainability, recycling and reuse) have an important role to play.

To develop products for the circular economy, collaborative design activity affecting two or more supply chain partners becomes the norm. When analysing the circular economy products of eight companies in the textile sector, Franco (2017) found that co-design practices were essential. Three types of collaboration were observed: (1) modification or substitution of chemicals for yarn and fabric manufacturing, (2) co-development of circular materials and component parts, and (3) customisation of existing materials for new textile applications. The interdependency was strong, with firms relying on the competencies of their supply chains in order to achieve innovation. A robust approach to both product and process design is needed to deliver circular economy goals.

\section{Extended Producer Responsibility in textile sector}

To date, only France has introduced legislation on EPR for apparel, linen and shoe products. There are voluntary initiatives in several countries, and some companies have voluntarily developed strategies influenced by circular economy concepts. However, it is fair to observe that the business models of most apparel companies are silent about end-of-life issues. Nevertheless, the concepts of EPR and CE are being actively explored and each year that passes brings significant additions to the discussion.

The European Commission is supporting a transition to a Circular Economy (European Commission, 2015). The Press Release was optimistic in tone, anticipating benefits for both the environment and the economy. The funding package would contribute to "broad political priorities by tackling climate change and the environment while boosting job creation, economic growth, investment and social fairness." Targets were set, notably a 
common EU target for recycling $65 \%$ of municipal waste by 2030 , and a landfill target to reduce landfill to maximum of $10 \%$ of municipal waste by 2030 .

Subsequent debate has been mixed. Some gave strong support to the transition, arguing for more stringent targets and greater use of EPR. Others questioned the economic arguments and suggested that the targets were unrealistic. It was pointed out that 'circular' solutions do not necessarily lead to sustainable outcomes. All waste materials are affected by some form of downgrading, and there must be a cost when we seek to turn wastes into resources for the next economic cycle. In most cases, these costs are non-trivial and there must be a business case if recycling is to proceed. As expressed by de Man and Friege (2016): "Creating endless material cycles without continuously adding energy would be counter to the Second Law of Thermodynamics." One way to quantify the challenge for industry is to use Life Cycle Analysis (LCA). An example is provided by Bjørn and Strandesen (2011:9) who found that a proposed Cradle to Cradle (C2C) processing route was not sustainable:

"It can be concluded that products designed after the $\mathrm{C} 2 \mathrm{C}$ concept are not always sustainable. This is highly influenced by the fact that the sustainability of products greatly depends on external systems such as energy supply and waste management infrastructure."

Of course, these "external systems" are not unalterable, and the situation can be greatly improved by product and process design. However, there is no magic wand to ensure that the CE pathway is either sustainable or cost-effective - these goals emerge only by rigorous research and development. This brings us to the other assumption discussed by de Man and Friege (2016): that 'circular' solutions are available and can be realised in practice. The lessons from experience, although limited, reveal that implementation of CE strategies is difficult. The goal of $100 \%$ circularity is an unrealistic ideal. EPR has had more of an impact on WEEE producers than any other sector, and yet these companies have not reached the stage where all wastes become resources.

"Not surprisingly, studies on electronic consumer products have shown that recovering all materials present in a certain product in their original grade is not possible without creating substantial additional environmental impacts." (de Man and Friege, 2016, 94)

Further impediments to the circular use of material resources are discussed by Velis (2018). One paragraph particularly is worth noting here.

"While 'circular economy' contains the term 'economy', strangely enough, it is not necessarily a theory about economics - macro or micro - but mainly a theory for how to manage material flows. The concept enjoys little traction and understanding among the current theoretical economists, both orthodox and heterodox. This one may sound a bit academic - but, it is not as such. We need to ensure that the actual and perceived societal benefits of a new circular model are established in a more fundamental and sound manner than just traditional cost-benefit analysis, which is an insufficient tool to describe transformation at a systems level. Maybe heterodox economics looking at how to analyse a system of systems (e.g. systems of provision) or the environmental economics explicitly considering internalisation of the 'externalities', are a sounder basis to discuss how a circular economy could perform as a whole and for the future economies of our World." (Velis, 2018, 759)

This point has relevance to assertions that wastes have value. Materials do not have an inherent value until there are people who are prepared to put a value on them. In a Circular Economy, there are processing pathways in place to convert wastes to something that people or organisations are prepared to purchase.

The European Commission has funded several research projects to help implement CE among member states. These include:

- Resyntex (2018) aims to create a new circular economy concept for the textile and chemical industries. Using chemical processing of unwearable textile waste, the outputs are chemical feedstocks supplying other industrial sectors.

- Trash-2-Cash (2018) aims to create new regenerated fibres from pre-consumer and post-consumer waste. The project is also pioneering a new collaborative Design Driven Material Innovation (DDMI) methodology, a whole new way of developing materials.

- $\quad$ R2 $\pi$ (2018) examines ways to shift from the broad concept of a Circular Economy to one of Circular Economy Business Models (CEBM) while searching for both market failures and policy failure that hinder the broad implementation, use, and acceptance of CEBMs.

Additionally, other relevant projects are:

- Worn Again Technologies (2018) are developing a polymer recycling technology that can separate, decontaminate and extract polyester polymers, and cellulose from cotton, from non-reusable textiles 
and PET bottles and packaging and turn them back into new textile raw materials as part of a continual cycle.

- $\quad$ re:newcell (2018) has developed recycling technology to dissolve used cotton and other natural fibres into a new, biodegradable raw material, re:newcell pulp. This can be turned into textile fibre, be fed into the textile production cycle and meet industry specifications.

- Relooping Fashion Initiative (2018) uses a cellulose dissolution technique to process worn-out cotton clothing and to generate new fibres, yarns and garments. The Initiative has developed a circular economy business model to coordinate the contributions of companies and consumers.

The net effect of all these projects is to lay the foundations for informed choices about CE implementation. It is essential that the technologies deliver the needed material transformations, and it is also vital that businesses investing in CE can identify a route to achieve profitability and an adequate return on investment. Some of the projects are focused on fibre-to-fibre recycling, whereas others are broadening the scope of CE by using wastes from one sector to be transformed into feedstocks for other industrial sectors. Both of these options are legitimate implementations of $\mathrm{CE}$.

In 2017, Mistra Future Fashion published a report that evaluated two different policies to promote the fibre-tofibre recycling of textiles in Sweden. These were a mandatory extended producer responsibility scheme and a refunded virgin payments (RVP) system. In the case of RVP, there would be producer charges for virgin fibre usage with refunds based on use of recycled textile fibres. The report (Elander et al. 2017) recognised that numerous changes in practice would be necessary, but found more positive outcomes with EPR than with RVP.

In May 2018, the European Parliament approved "a set of ambitious measures to make EU waste legislation fit for the future, as part of the EU's wider circular economy policy." The measures included the promotion of the use of economic instruments, including Extended Producer Responsibility schemes. Household textile wastes are required to be collected separately by 2025 . Member States are required to prioritize prevention, re-use and recycling above landfilling and incineration. The declared goal is to make "the circular economy a reality" (European Commission, 2018b). Clearly, fiscal and legislative drivers are to be used to promote the policy.

Recognising that there are major challenges adding value to textile wastes, Tyler and Hall (2018) have modelled the costs identified as part of the Resyntex project. Preliminary work suggested that the business case for CE technologies and processes was not strong enough to attract potential investors. Drawing on the concept of industrial ecosystem services, it is possible to identify benefits not normally costed when making a financial appraisal. Some of these services can be measured financially, whereas others are indirect and can only be quantified by incorporating policy-related assumptions. When textile ecosystem services are quantified and incorporated into the business model, the outcome for $\mathrm{CE}$ is considerably more healthy. However, to attract the significant investment needed, the conclusion is drawn that an EPR subsidy of the processing costs is needed to turn the concept into a reality.

\section{Culture change for Circular Economy}

The linear model of production has been popularised as "take - make - dispose". This format has worked when natural resources are plentiful and disposal is not an issue. However, natural resources are finite and the disposal of unwanted materials is a significant problem all around the world. According to MacArthur:

"Within the past decade, however, businesses have been hit by an increase in commodity prices that has effectively erased the (average) decline of the entire preceding century. Coupled with this, we expect three billion more middle-class consumers by 2030. This unprecedented rise in demand for a finite supply of resources calls into question our current predominantly linear economic system" (Ellen MacArthur Foundation, 2014, 3).

According to this report, it is necessary to address the problems of "leakage" of materials and product flows outside the framework of a circular system. It sets out to identify the many barriers to circularity associated with the phenomenon of "linear lock-in", described as "the engrained structures that have anchored themselves around our linear-based growth models" (p.29).

Moving from linear to circular flows requires a culture change at all stages of the supply chain, including consumers and the waste industry. This represents a paradigm shift affecting the whole sector. Consequently, implementation of the Circular Economy necessarily brings disruption to existing linear supply chains.

"The circular economy is of academic interest for its potential as a disruptive, innovative economic model that relates to government policy, businesses, and consumers. It is restorative and regenerative by design, structure, and objective: products, components, and materials are designed to continuously 
add, recreate, and preserve value at all times. The circular economy is disruptive as it changes the incumbent model and forces a rethinking of the many various aspects of production and consumption across the entire production and consumption chain" (Esposito et al., 2018, 6).

A review of two decades of CE implementation concluded that the worldwide picture is one of initiation, mainly addressing recycling rather than reuse. The initiatives studied pointed to the need for culture change that is comprehensive in scope:

"The lesson learned from successful experiences is that the transition towards CE comes from the involvement of all actors of the society and their capacity to link and create suitable collaboration and exchange patterns. (Ghisellini et al. 2016).

Whilst recycling is an integral part of the CE framework, the reuse of products is not a hallmark of CE. Reuse can and does take place in linear supply chains and does not imply that a culture change has been achieved. It can mean only that discarded products have residual value making it feasible for businesses to sort and resell the products. At present, the economic case for reuse is significantly stronger than for recycling, suggesting that financial drivers as well as regulation are needed for companies to commit to recycling. Technical innovation is also needed, as beneficial environmental impacts of recycling and reuse are not always found:

"The reviewed publications provide strong support for claims that textile reuse and recycling in general reduce environmental impact compared to incineration and landfilling, and that reuse is more beneficial than recycling. The studies do, however, expose scenarios under which reuse and recycling are not beneficial for certain environmental impacts" (Sandin and Peters, 2018).

The focus of this chapter is on design and the product development process. There is potential for design decisions to radically change the extent to which technological and economic barriers impede the transition to circularity. The problem faced by most retailers and brand owners is that their design processes are dominated by the aesthetic considerations of seasonal colour and style trends, and the availability of novel fashion fabrics. Furthermore, there is the continuous pressure to reduce lead times for range and product development. To a large extent, the technical skills required for sampling, product development and fabric procurement are provided by global partners.

When tools of Design for Environment and Design for Disassembly and Disposal are introduced, numerous technical issues need to be addressed. This represents a significant culture change. In other industrial sectors, a team-based product development process has been found to address the challenges, whereby designers work alongside specialists from other disciplines (Tyler, 2008a, 2008b). Underpinning teamworking is the concept of concurrent product development, which requires culture change in the thinking of most brand owners, and a departure from the practice of separating the design process from the product development process. In most cases, this will bring disruption to any globalised industrial sector.

There are designers who are giving a lead about these issues and acknowledging the importance of culture change in their own discipline. The example that follows comes from Andrews (2015: 312):

"Designers cannot wait for the development of a remanufacturing, reuse and/or recycling infrastructure and other alternative business models, however, before they start to design for the Circular Economy; they must anticipate and prepare for the alternative economy particularly where there is a long product lead time from initial concept to shop floor. Designers now have the opportunity to lead the paradigm shift and in addition to designing for the 'closed loop' they have the potential to influence business and consumer behaviour and consumption by extending actual product life and increasing perceived value of products. In order for this to happen, however, some designers need to change their practice while others need to change their practice and thinking."

\section{The French experience of adopting producer responsibility for apparel goods}

As noted in section 5, France has pioneered legislation on EPR for apparel, linen and shoe products. As from $1^{\text {st }}$ January 2007, companies offering garments, household linen and footwear to the French market are held responsible to taking them back, and then recycling or disposing of these products. The companies have a choice: either set up their own take-back programme (which has to be approved by the French public authority), or contribute financially to an accredited Producer Responsibility Organisation (PRO) that will act on their behalf. France has one PRO, which is a not-for-profit organisation, which collects tariffs from member companies based on the previous years' sales. A case study of this organisation, Eco TLC, is by Bukhari et al. (2018). This paper considers the first decade of Eco TLC's activity, identifying the many organisations that are contributing to textiles waste recovery in France, the collection and recycling processes, the impact of EPR and 
the barriers to further movement towards the circular economy. Much information about this PRO is accessible via its website (Eco TLC, 2018a), including annual reports.

The 2018 report gives an overview of the investment in recycling and the circular economy: "Since the initial call for project proposals was launched in 2010, Eco TLC has provided financial backing for 36 projects, amounting to a total commitment of $€ 3.2 \mathrm{M}$. A breakdown of the projects according to their state of progress indicates that 17 projects have been completed, 10 are ongoing and 9 are in the process of starting up" (Eco TLC, 2018b).

Most space in the annual reports is devoted to the project work, and there can be little doubt that these projects have made an impact for the companies concerned, and the PRO is providing a stimulus for innovation in the management of waste.

Bukhari et al. (2018) point out that the sorting of waste textiles in France was undertaken by 1,400 full-time workers, of which $49 \%$ were reserved for people facing employment difficulty. Eco TLC provides financial support for these otherwise excluded workers, not just to incentivise the sorting organisations, but also to buffer the financial volatility of the used clothing market. The commitment to this financial support is substantial: "by applying the tariff schedule, the PRO collected $€ 17.2$ million from the members (an average of $€ 0.0067$ per piece and $€ 28.7$ per tonne) in 2016. This contribution was used to cover the following 2015 expenses: $€ 477$ thousand spent in projects finance, $€ 2.1$ million subsidised local communities for consumer-awareness campaigns, $€ 12.8$ million in subsidies paid to charities and private organisations for sorting the collected textiles and clothing, and little budget spent in taxes, staff, offices and outsourced services" (Bukhari et al., 2018:327).

So, although the budget for projects is $€ 0.5 \mathrm{~m}$, over 4 times this amount is being spent on consumer-awareness campaigns, and over 25 times this amount is given as subsidies to sorting organisations. There is a mismatch between the messages communicated in the annual reports and the actual usage of the tariff contributions.

The Eco TLC tariffs include discounts for producers incorporating recycled materials into their products. The volumes are too low for producers to take the trouble to declare the quantities and certify the origin of the recycled materials. Furthermore:

"We observe that the PRO does not give producers incentives such as eco-module tariff when they ecologically design and source other materials" (Bukhari et al., 2018:329).

This comment gets close to the heart of the problem: the French EPR scheme is not incentivising producers to implement eco-design. There is no culture change for the producers - they pass over the sustainability issues to the PRO and to motivated suppliers. The drivers to use DfE and DfD tools are lacking. The organisation Eco TLC has shown what can be done with relatively small sustainability projects, but there is a fundamental weakness in that culture change in the design process of producers and brand owners is hard to discern.

\section{Conclusions.}

The quest for more sustainable products begins by defining desirable characteristics and seeking out ways of achieving them. It is found that the design function is central to greening products. As Section 3 demonstrates, there are solutions that designers can bring to the goals of increasing longevity, reducing the energy requirements for garment care, imparting multifunctional use and modularity, and selecting materials with low environmental impacts. To achieve these goals, a greater technical awareness is required when design decisions are made, together with significant collaboration within the supply chain. However, whilst all of these developments can be part of a circular economy, none of them actually close the loop. Consequently, producers of sustainable textile products do not necessarily move away from the conventional linear production pathways. Sustainability does not necessarily lead to culture change.

This chapter has argued that implementing the Circular Economy necessarily involves culture change, new tools and new collaborations. At the heart of the paradigm shift is the design process, which brings into view the way products are handled when they are worn out or no longer needed. In the circular economy, the unwanted materials become resources for the next production cycle. As Franco (2017) has shown, some companies have started to change their culture, but we are at a very early stage. The major projects identified in section 5 are an indication of immaturity, but provide some confidence that the textile Circular Economy is not a pipe dream.

As indicated in section 4, the centrality of design needs to be recognised, and designers find ways of operating with an awareness of the whole supply chain. The potential for teamworking in both design and product development has been noted. Co-design will be crucial, affecting the supply chain as a whole. 
The updated legal framework from the European Commission (2018b) is clear about the use of regulative drivers: "The new rules [.. . ] promote the use of economic instruments, such as Extended Producer Responsibility schemes." EPR has the potential to facilitate the financing of CE in its early stages, as discussed by Tyler and Hall (2018).

France has already a regulative driver, and Eco TLC recognises that eco-design is an integral part of the pathway to CE. However, by spending the bulk of its income on subsidising labour-intensive sorting, it is undermining its stated principles. (If the sorting process needs to be subsidised, the appropriate funding would appear to come from the social services budget).

To promote culture change, regulative drivers are not enough. There must be a clarity about why change is essential: its benefits and its challenges. To achieve this, educational programmes must make the connection between principles and purposeful actions.

\section{References}

Andrews, D. 2015. The circular economy, design thinking and education for sustainability. Local Economy, 30(3), 305-315.

Bhamra, T., Heeley, J. and Tyler, D. 1998. A cross-sectoral approach to new product development. The Design Journal, 1(3), 2-15.

Bjørn, A. and Strandesen, M. 2011. The Cradle to Cradle concept - is it always sustainable? Poster session presented at The Life Cycle Management (LCM) conference: Towards Life Cycle Sustainability Management, Berlin, Germany. Available at: http://orbit.dtu.dk/files/6443333/bjoern-the_cradle to_cradle_concept733 ax\%5BI\%5D.pdf [accessed September 2018]

Bocken, N. M. P., Olivetti, E. A., Cullen, J. M., Potting, J. and Lifset, R. 2017. Taking the Circularity to the Next Level: A Special Issue on the Circular Economy. Journal of Industrial Ecology, 21(3), 476-482.

Bukhari, M.A., Carrasco-Gallego, R. and Ponce-Cueto, E. 2018. Developing a national programme for textiles and clothing recovery. Waste Management \& Research, 36(4), 321-331.

Carpet Recycling UK. 2018. Available at: http://www.carpetrecyclinguk.com/our_achievements.php [accessed September 2018]

Choi, T. 2017. Environmental impact of voluntary extended producer responsibility: The case of carpet recycling. Resources, Conservation and Recycling, 127, 76-84.

Connor-Crabb, A., Miller, K. and Chapman, J. 2016. Design Strategies for the Eternal Reoccurrence of the New. Fashion Practice, 8(1) 22-43.

Cooper, T., Hill, H., Kininmonth, J., Townsend, K., Hughes, M., Knox, A. and Fisher, T. 2013. Design for Longevity: Guidance on increasing the active life of clothing. WRAP (Waste \& Resources Action Programme), Banbury.

de Man, R. and Friege, H. 2016. Circular economy: European policy on shaky ground. Waste Management \& Research, 34(2), 93-95.

Defra, 2011. Environmental Protection Act (Summary). Available at:

http://adlib.everysite.co.uk/adlib/defra/content.aspx?doc=18386\&id=18388 [accessed September 2018]

Eco TLC (2018a). Available at: http://www.ecotlc.fr/ [accessed September 2018]

Eco TLC (2018b). Roads to Innovation 2018, Available at:

http://www.ecotlc.fr/ressources/Documents_site/7_2018_Chemins_Innovation_GB_BD.pdf [accessed September 2018] 
Ellen MacArthur Foundation, 2014. Towards the Circular Economy: Accelerating the scale-up across global supply chains. World Economic Forum, Geneva, Switzerland. Available at:

http://www3.weforum.org/docs/WEF_ENV_TowardsCircularEconomy_Report_2014.pdf [accessed September 2018]

European Commission, 2015. Closing the loop: Commission adopts ambitious new Circular Economy Package to boost competitiveness, create jobs and generate sustainable growth. Brussels, 2 December 2015. Available at: http://europa.eu/rapid/press-release IP-15-6203 en.htm. [accessed September 2018]

European Commission, 2018a. REACH Implementation. Available at:

http://ec.europa.eu/environment/chemicals/reach/implementation_en.htm [accessed September 2018]

European Commission, 2018b. Circular Economy: New rules will make EU the global front-runner in waste management and recycling. Brussels, 22 May 2018. Available at: http://europa.eu/rapid/press-release IP-18-

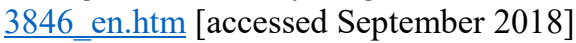

Esposito, M., Tse, T. and Soufani, K. 2018. Introducing a Circular Economy: new thinking with new managerial and policy implications. California Management Review, 60(3), 5-19.

Franco, M.A. 2017. Circular economy at the micro level: A dynamic view of incumbents' struggles and challenges in the textile industry. Journal of Cleaner Production, 168(1), 833-845.

Gardner, J. 2017. Carpet recycling UK - Recovering value from carpet fibres. Proceedings of the 6th International Fibre Recycling Symposium, Manchester, June 2017. Paper 18, 7 pages.

Gereffi, G. 1999. International trade and industrial upgrading in the apparel commodity chain. Journal of International Economics, 48(1), 37-70.

Ghisellini, P., Cialani, C. and Ulgiati, S. 2016. A review on circular economy: the expected transition to a balanced interplay of environmental and economic systems, Journal of Cleaner Production, February 2016, $114,11-32$.

Gracey, F. and Moon, D. 2012. Valuing Our Clothes : the evidence base. Waste and Resources Action Programme.

Heys, R. 2012. The Clean Air Act 1956. BMJ, 345: e5751

Kirchherr, J., Reike, D. \& Hekkert, M. 2017. Conceptualizing the circular economy: An analysis of 114 definitions. Resources, Conservation and Recycling, 127, 221-232.

Long, E., Kokke, S., Lundie, D., Shaw, N., Ijomah, W. and Kao, C. 2016. Technical solutions to improve global sustainable management of waste electrical and electronic equipment (WEEE) in the EU and China. Journal of Remanufacturing, December 2016, 6:1

Elander, M., Tojo, N, Tekie, H. and Hennlock, M. 2017. Impact assessment of policies promoting fiber-to-fiber recycling of textiles. Mistra Future Fashion, Number: 2017:3

Gwilt, A. 2014. A Practical Guide to Sustainable Fashion. London: Bloomsbury.

niaga. 2018. Available at: https://www.dsm-niaga.com/ [accessed September 2018]

Mugge, R., Schoormans, J. P. L. and Schifferstein, H. N. J. 2005. Design strategies to postpone consumers' product replacement: The value of a strong person-product relationship. Design Journal, 8(2), 38-48.

Niinimäki, K. 2010. Eco-Clothing, Consumer Identity and Ideology. Sustainable Development, 18, $150-162$.

Niinimäki, K. (ed.) 2013. Sustainable Fashion: new approaches. Helsinki: Aalto University.

Our Common Future, 1987. Report of the World Commission on Environment and Development. Available at: http://www.un-documents.net/our-common-future.pdf [accessed September 2018] 
Park, H. and Armstrong, C. M. J. 2017. Collaborative apparel consumption in the digital sharing economy: An agenda for academic inquiry. International Journal of Consumer Studies, 41(5), 465-474.

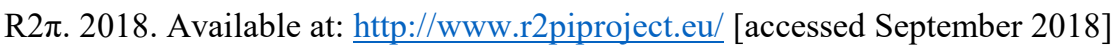

Relooping Fashion Initiative. 2018. Available at: http://reloopingfashion.org/ [accessed September 2018]

re:newcell. 2018. Available at: https://renewcell.com/ [accessed September 2018]

Resyntex. 2018. Available at: http://www.resyntex.eu/ [accessed September 2018]

Sandin, G. and Peters, G.M. 2018. Environmental impact of textile reuse and recycling - a review. Journal of Cleaner Production, 184, 353-365.

Spangenberg, J. H. and Lorek, S. 2002. Environmentally sustainable household consumption: From aggregate environmental pressures to priority fields of action. Ecological Economics, 43(2-3), 127-140.

Trash-2-Cash. 2018. Available at: https://www.trash2cashproject.eu/ [accessed September 2018]

Tyler, D.J. (ed). 2008a. Carr \& Latham's Technology of Clothing Manufacture, 4th edition, Blackwell Publishing, Oxford, Chapter 9.

Tyler, D. 2008b. Advances in apparel product development, in Fairhurst, C. (ed), Advances in apparel production, Woodhead Publishing Ltd., Cambridge. 157-176.

Tyler, D. and Hall, N. 2018. Eco-System Services and the Circular Economy for Textiles, The 91st Textile Institute World Conference, July 23 - July 26 2018, Leeds University, UK.

Velis, C. 2018. No circular economy if current systemic failures are not addressed, Waste Management \& Research, 36(9), 757-759.

Wang, H., Gu, Y., Li, L., Liu, T., Wu, Y. and Zuo, T. 2017. Operating models and development trends in the extended producer responsibility system for waste electrical and electronic equipment. Resources, Conservation and Recycling, 127, 159-167.

Worn Again Technologies. 2018. Available at: http://wornagain.info/ [accessed September 2018]

WRAP. 2018. WRAP and the Circular Economy. Waste and Resources Action Programme. Available at: http://www.wrap.org.uk/about-us/about/wrap-and-circular-economy [accessed September 2018]

Zane, D. M., Irwin, J. R. and Reczek, R. W. 2016. Do less ethical consumers denigrate more ethical consumers? The effect of willful ignorance on judgments of others. Journal of Consumer Psychology, 26(3), 337-349 